\section{Oro-Motor Intervention \\ Protocol to Improve Sucking \\ Behavior among Neonates \\ with Immature Sucking: An \\ Experimental Protocol}

RAMYA CHANDRAN (D)

JAGATHEESAN ALAGESAN (D)

*Author affiliations can be found in the back matter of this article

\section{ABSTRACT}

Background: Oro-motor intervention methods were previously adopted to improve the sucking pattern but there is still a lag in the structured protocol for improving sucking behavior in infants with immature sucking. Thus, this study is aimed to develop a structured protocol for the Oro-motor intervention to improve sucking behavior.

Method: Using the prospective observational study design, neonates with poor suck (producing less than 10 sucks per minute), under NG tube feeding, and maintaining oxygen saturation at room air were included. A total of 6 subjects were enrolled in this study and they were treated with Oro-motor intervention protocol. The Sucking rate and LATCH score were taken as the outcome measures and measured at beginning of intervention and after 2 weeks of intervention.

Result: The mean pre-test and post-test values for sucking rate were is (8.66), (32.5) and LATCH were (4.66), (8.16) respectively. The data collected showed that the protocol framed for Oro-motor intervention was significantly effective in improving quality of feeding among infants with immature sucking behavior.

Conclusion: The structured Oro-motor intervention protocol improves the feeding performance in infants with poor sucking behavior and improves the LATCH score. All the infants included in this study where under nasogastric tube feeding, thus the structured protocol can be considered to be helpful in weaning from NG tube feeding.

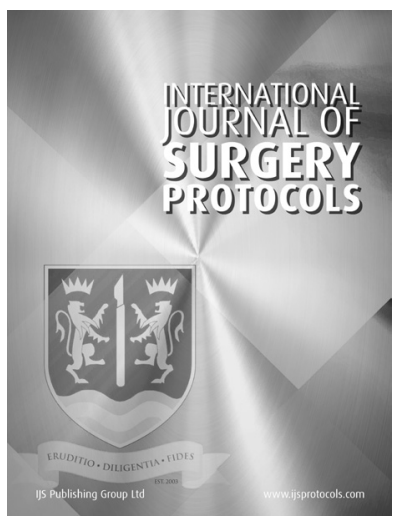

PROTOCOL

\section{IJS Press}

Part of the IJS Publishing Group
CORRESPONDING AUTHOR:

\section{Ramya Chandran}

Saveetha College of physiotherapy, Saveetha Institute of Medical and Technical Sciences, Chennai, Tamilnadu, India

ramyachandran3396@gmail. com

KEYWORDS:

sucking behavior; pacifier; infant nutrition disorders; newborn

TO CITE THIS ARTICLE: Chandran R, Alagesan J. Oro-Motor Intervention Protocol to Improve Sucking Behavior among Neonates with Immature Sucking: An Experimental Protocol. International Journal of Surgery: Protocols. 2021; 25(1), pp. 129-134. DOI: https://doi. org/10.29337/ijsp.152 


\section{INTRODUCTION}

Effective direct breastfeeding provides short and long duration benefit to mother as well as infant [1]. Direct breastfeeding is the natural method of infant feeding through the mother's nipple to infant's mouth which is needed for first six to seven months of infant life. Direct breastfeeding not only fulfills the nutritional status of the infants but also necessary to gain adequate immunity against infections such as meningitis, pneumonia, diarrhea, and reduces mortality rate in infant [2, 3]. Direct breastfeeding helps for appropriate weight gain in neonates and reduces length of stay in the hospital [4].

Sucking pattern usually composed of synchronized rhythmic suck, swallow and breathing. It contains alternate suck and expression [5, 6]. Nutritive and nonnutritive are the two variations in sucking $[7,8]$. Primitive reflex sucking develops at 28 weeks of gestation, preterm infants might have immature primitive sucking reflex and leads to poor weight gain during the neonatal period [9, 10]. Major cause for poor sucking includes preterm birth, neonates with low birth weight, cleft lip, cleft palate and some other congenital abnormalities [11-13]. Term neonates also have poor sucking because of mother experiencing medical complication during antenatal period, intra ventricular hemorrhage and due to type of delivery. Poor sucking behavior refers to the reduced milk intake capacity of the infant resulting in malnutrition. The LATCH scale was designed to quantitatively measure the feeding capability of both mother and the infant, thus reduced latch scores were considered to be a major sign of poor sucking behavior leading to complications such as high risk of aspiration and infections like pneumonia [14]. Neonates with feeding difficulty may be in nasogastric tube to avoid such incidence. Traditional methods help in improving feeding pattern in neonates $[15,16]$.

Sucking pattern was observed during direct breast feeding, the movement of the jaw was noted and it was considered as 1 suck during the observation process. Various treatment methods were previously adopted to improve the sucking pattern, but there is still a lag in the structured protocol for improving sucking behavior in infants with immature sucking [17-19]. Thus, the research question of this study was to determine whether there is any significant effect of structured Oro-motor intervention protocol to improve sucking behavior among infants with poor sucking behavior, with a hypothesis that the Oro-motor intervention will be significantly effective in improving sucking behavior.

\section{METHOD \\ STUDY DESIGN}

This was a prospective observational study.

\section{SAMPLE TYPE}

Purposive sampling was done.

\section{STUDY SETTING AND DURATION OF THE STUDY}

Study was conducted at the physiotherapy department of Saveetha medical college and hospital (SMCH) in collaboration with the Neonatal intensive care unit (NICU) of the Pediatrics department, SMCH, Chennai, Tamilnadu, India during the period between the beginning of January 2021 and the end of March 2021.

\section{ETHICAL AND CONSENT}

This Prospective observation study was approved from Institutional Scientific Review Board, in saveetha institute of medical and technical science (27/03/2020/ISRB/MPT/ SCPT). Informed consent in written format was obtained from the parents of neonates enrolled in this study after explaining about the study procedure.

\section{SELECTION CRITERIA}

All preterm and term neonates with poor sucking were included in this study through referral from the neonatologists. The inclusion criteria were to include neonates having poor suck (producing less than 10 sucks per minute), Neonates feeding through NG tube, without respiratory distress and maintaining oxygen saturation at room air. Whereas, neonates with respiratory complications, intraventricular hemorrhage, neonates under mechanical ventilator, congenital malformations such as cleft lip or cleft palate, and mothers with breast abnormalities were excluded the flowchart representing the selection process is shown in Figure 1.

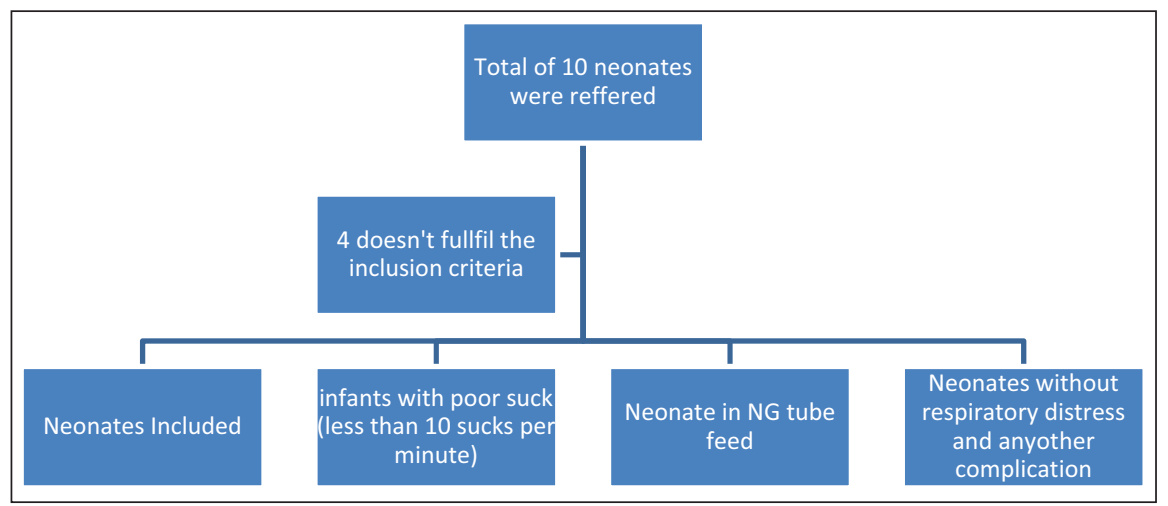

Figure 1 Flowchart representing the selection process. 


\section{DATA COLLECTION}

A total of 6 subjects were enrolled in this study and they were treated with Oro-motor intervention protocol. Outcome measures were sucking rate, and LATCH score. Each subject's sucking rate was recorded by two methods. Asking number of sucks felt by the mother per minute using stopwatch and another through gloved finger by the therapist per minute using stopwatch.

Sucking rate per minute was calculated before the intervention. Number of sucks felt by the mother was calculated during direct breast-feeding after the intervention. Sucking rate was measured before the intervention daily, sucking rate was measured using a stopwatch for continuous 3 minutes and the average value of 2 nd minute was taken into consideration [20].

The LATCH scale consists of five different assessments (latching, audible swallowing, nipple type, comfort, and hold) with scores of 0 to 10 , indicating poor sucking to normal sucking. Both the sucking rate and the LATCH scores were collected at the first day of intervention and after 2 weeks of intervention as the pre-test and posttest values respectively [21].

\section{Oro-motor intervention protocol}

- Oro-motor intervention is essential for preterm and term neonates with sucking difficulty.

- Criteria: Neonates are enrolled if they produce less than 10 sucks per minute.

- Before starting the procedure assess for rooting reflex. If neonate doesn't initiate rooting then therapy begins with initiation of rooting followed by perioral and intraoral stimulation.
- Precautionary measures before Oro-motor intervention: Monitor vital signs (Temperature, $\mathrm{SpO}_{2}$, Pulse Rate, Heart rate, Blood Pressure). Any external appliances (Ventilator, OG tube, Oxygen mask, Incubator). Any Congenital Facial Anomalies.

\section{STATISTICAL ANALYSIS}

The Means and standard deviations of the collected data were calculated at pre-test and post-test of all the 6 samples, sucking rate $(8.66+/-3.24),(32.5+/-10.46)$ and LATCH scores $(4.66+/-0.47),(8.16+/-1.46)$. The values were statistically analyzed using paired t-test to determine the null hypothesis and the data analysis will be considered significant if the $p$ value $<0.05$.

\section{RESULTS}

Both term and preterm neonates enrolled in this study with the male female ratio of 4:2. Irrespective of their birth weight neonates with sucking difficulty and on nasogastric tube feed are enrolled in this study. The study was aimed to determine the effect of Oro-motor intervention protocol on immature sucking behavior. Sucking rate counted for continuous 3 minutes and average value of 2 nd minute was taken in this study and LATCH score of Pre-test was tabulated in Table 1. After 2 weeks of intervention the post-test value of sucking rate and LATCH score were collected and tabulated in Table 2.

The mean pre-test and post-test values of sucking rate were (8.66), (32.5) and LATCH were (4.66), (8.16) respectively. The table $t$ value was calculated using paired t-test and represented in Table 3. The calculated $t$

\begin{tabular}{|c|c|}
\hline STIMULTION & PROCEDURE \\
\hline Perioral & $\begin{array}{l}\text { Buccinators muscle massage: Massage given in anticlockwise and clockwise direction }[19,28] \text {. ( } 1 \text { min) } \\
\text { Compression: Given from ear to corner of the mouth in both right and left cheeks ( } 1 \mathrm{~min}) \text {, upper lip from base to the nose } \\
\text { to corner of the lips and lower lip from base of the chin to corner of the lower lip (1 } \mathrm{min})[19,30] \text {. } \\
\text { Duration: } 3 \text { minutes. }\end{array}$ \\
\hline Intraoral & $\begin{array}{l}\text { Mild stroking done on the hard palate ( } 1 \mathrm{~min} \text { ), side of the gums and then on the tongue with little finger (1 } \mathrm{min}) \text { [19]. } \\
\text { Duration: } 2 \text { minutes }\end{array}$ \\
\hline
\end{tabular}

Table 1 Intervention protocol.

\begin{tabular}{lllllll}
\hline SUBJECT & GESTATIONAL AGE & GENDER & BIRTH WEIGHT & TUBE FEEDING & SUCKING RATE/MINUTE & LATCH \\
\hline 1 & 35 weeks & Male & 2.460 & NG tube & 8 & 5 \\
\hline 2 & 34 weeks + 4 days & Female & 2.00 & NG tube & 9 & 4 \\
\hline 3 & 31 weeks + 3 days & Male & 1.600 & NG tube & 14 & 5 \\
\hline 4 & 38 weeks & Male & 3.100 & NG tube & 4 & 4 \\
\hline 6 & 36 weeks + 4 days & Female & 2.150 & NG tube & 11 & 5 \\
\hline
\end{tabular}

Table 2 Baseline criteria of 6 subjects. 


\begin{tabular}{llll}
\hline SUBJECT & GENDER & SUCKING RATE/MINUTE & LATCH \\
\hline 1 & M & 40 & 10 \\
\hline 2 & F & 33 & 8 \\
\hline 3 & M & 47 & 10 \\
\hline 4 & M & 15 & 6 \\
\hline 5 & F & 36 & 8 \\
\hline 6 & M & 24 & 7 \\
\hline
\end{tabular}

Table 3 Post-test value of sucking rate and LATCH score.

\begin{tabular}{llllll}
\hline \multirow{2}{*}{ S.NO } & OUTCOME MEASURES & $\begin{array}{l}\text { PRE-TEST MEAN }+/- \\
\text { STANDARD DEVIATION }\end{array}$ & $\begin{array}{l}\text { POST-TEST MEAN }+/- \\
\text { STANDARD DEVIATION }\end{array}$ & T-VALUE & P-VALUE \\
\hline 1 & Sucking rate & $8.66+/-3.24$ & $32.5+/-10.46$ & 6.96 & 0.0009 \\
\hline 2 & LATCH score & $4.66+/-0.47$ & $8.16+/-1.46$ & 6.216 & 0.0016 \\
\hline
\end{tabular}

Table 4 Pre-test and post-test comparison.

value of sucking rate was 6.96 , at $p$ value $<0.05$, similarly the calculated t-value of LATCH score was 6.216 at $p$ value $<0.05$. Thus, both the results were statistically significant indicating the sucking rate and LATCH scores were improved after 2 weeks of intervention among infants with immature sucking behavior (Table 4).

From the statistical analysis the data collected showed that the protocol framed for Oro-motor intervention was significantly effective in improving quality of feeding in infants with immature sucking behavior.

\section{DISCUSSION}

Various treatment methods were previously adopted to improve the sucking pattern such as music, auditory, vestibular and tactile stimulation and stroking to improve non-nutritive sucking [17-19], but there is still a lag in the structured protocol for improving sucking behavior in infants with immature sucking. Thus, the purpose of this study is to develop a structured protocol for the Oromotor intervention to improve sucking behavior.

Advanced treatment techniques were also have been available but still they need an experienced person for clinical practice [22-27]. Medoff-Cooper B et al, used multisensory approach to improve sucking pattern such as auditory, tactile and vestibular stimulation to improve feeding performance in infants [18]. Similar to our study, Fucile et al, used peri-oral and intra-oral stimulation to improve feeding in preterm infants, which showed significant improvements in overall milk intake, rate at which the milk transfer that is milliliter per minute and amplitude of expression in $\mathrm{mmHg}$, thus the methods used in the structured protocol may also be effective in improving milk intake rate and milk transfer [28].
Gaebler CP et al, used stroking and perioral and intraoral stimulation as pre feeding protocol but there is a lag in exact duration in which the procedure to be followed [19]. Infants with sucking difficulty have a risk of oropharyngeal milk aspiration. Early intervention aimed to improve the sucking behavior in such infants [29]. To prevent aspiration some neonates have been in nasogastric tube in NICU, future they might have risk of infection spread $[15,16]$. Neonates without initiation of sucking reflex or delay in sucking behavior may develop speech difficulty [6].

Because of the methodological limitations, only 6 infants were included in the study. This might have resulted in a weak statistic (i.e., a small sample size). However, the current study suggests that the intervention may in fact be improving the sucking behavior, the small sample size in the study was considered as the major limitation. This raises queries whether significant statistical difference could be obtained in a larger sample size. Another possibility is that the outcomes used in this study were not sufficiently sensitive to adequately measure the intervention effect on sucking behavior. The use of more sensitive instruments such as real-time observation techniques, and sucking apparatus would be helpful in clarifying the results.

Oro-motor intervention protocol begins with monitoring the vitals followed by initiation of rooting reflex, perioral and intraoral stimulation. Subjects in this study presented with sucking difficulty during direct breast-feed, due to prematurity sucking reflex is not completely matured, and because of post natal complications such as encephalopathy, seizure disorder and respiratory distress syndrome, neonates have difficulty in maintaining rhythmic pattern of suckswallow-breath during direct breast feeding. 


\section{CONCLUSION}

The current study analyzed the effectiveness of the structured Oro-motor intervention protocol and shows improvement in feeding performance of infants with poor sucking behavior and improves the LATCH score. All the infants included in this study where under nasogastric tube feeding, thus the structured protocol can be considered to be helpful in weaning from NG tube feeding. However, further studies with large sample size and randomization are needed to determine the absolute effect of the current Oro-motor intervention protocol.

\section{COMPETING INTERESTS}

The authors have no competing interests to declare.

\section{AUTHOR AFFILIATIONS}

Ramya Chandran (iD) orcid.org/0000-0002-4236-967X Saveetha College of physiotherapy, Saveetha Institute of Medical and Technical Sciences, Chennai, Tamilnadu, India

Jagatheesan Alagesan (D) orcid.org/0000-0002-8428-1772 Saveetha College of physiotherapy, Saveetha Institute of Medical and Technical Sciences, Chennai, Tamilnadu, India

\section{REFERENCES}

1. Stuebe A. The risks of not breastfeeding for mothers and infants. Reviews in obstetrics and gynecology. 2009; 2(4): 222.

2. Stuebe AM, Schwarz EB. The risks and benefits of infant feeding practices for women and their children. Journal of Perinatology. 2010 Mar; 30(3): 155-62. DOI: https://doi. org/10.1038/jp.2009.107

3. Vohr BR, Poindexter BB, Dusick AM, McKinley LT, Wright LL, Langer JC, Poole WK. Beneficial effects of breast milk in the neonatal intensive care unit on the developmental outcome of extremely low birth weight infants at 18 months of age. Pediatrics. 2006 Jul 1; 118(1): e115-23. DOI: https://doi.org/10.1542/peds.2005-2382

4. Hausman BL. Mother's milk: Breastfeeding controversies in American culture. Psychology Press; 2003.

5. Bu'Lock F, Woolridge MW, Baum JD. Development of coordination of sucking, swallowing and breathing: ultrasound study of term and preterm infants. Developmental Medicine \& Child Neurology. 1990 Aug; 32(8): 669-78. DOI: https://doi. org/10.1111/j.1469-8749.1990.tb08427.x

6. Barlow SM, Estep M. Central pattern generation and the motor infrastructure for suck, respiration, and speech. Journal of communication disorders. 2006 Sep 1; 39(5): 366-80. DOI: https://doi.org/10.1016/j.jcomdis.2006.06.011
7. Veissier I, De Passillé AM, Després G, Rushen J, Charpentier I, Ramirez De La Fe AR, Pradel P. Does nutritive and non-nutritive sucking reduce other oral behaviors and stimulate rest in calves? Journal of animal science. 2002 Oct 1; 80(10): 2574-87. DOI: https://doi. org/10.1093/ansci/80.10.2574

8. Turgeon-O'Brien H, Lachapelle D, Gagnon PF, Larocque I, Maheu-Robert LF. Nutritive and nonnutritive sucking habits: a review. ASDC journal of dentistry for children. 1996 Sep 1; 63(5): 321-7.

9. McBride MC, Danner SC. Sucking disorders in neurologically impaired infants: assessment and facilitation of breastfeeding. Clinics in perinatology. 1987 Mar 1; 14(1): 10930. DOI: https://doi.org/10.1016/S0095-5108(18)30784-X

10. Ross ES, Browne JV. Feeding outcomes in preterm infants after discharge from the neonatal intensive care unit (NICU): a systematic review. Newborn and Infant Nursing Reviews. 2013 Jun 1; 13(2): 87-93. DOI: https://doi. org/10.1053/j.nainr.2013.04.003

11. Vyacheslavovich GA, Valentinovich PI, Evgenievna SE, Igorevna PN. Differentiated Speech Therapy Massage in a Complex System of Overcoming Dysphagia. Revista Latinoamericana de Hipertensión. 2019; 14(1): 43-54.

12. Reid J, Kilpatrick N, Reilly S. A prospective, longitudinal study of feeding skills in a cohort of babies with cleft conditions. The Cleft palate-craniofacial journal. 2006 Nov; 43(6): 702-9. DOI: https://doi.org/10.1597/05-172

13. Wagener S, Rayatt SS, Tatman AJ, Gornall P, Slator R. Management of infants with Pierre Robin sequence. The Cleft palate-craniofacial journal. 2003 Mar; 40(2): 180-5. DOI: https://doi.org/10.1597/15451569(2003)040<0180:MOIWPR>2.0.CO;2

14. Finer NN, Robertson CM, Richards RT, Pinnell LE, Peters KL. Hypoxic-ischemic encephalopathy in term neonates: perinatal factors and outcome. The Journal of pediatrics. 1981 Jan 1; 98(1): 112-7. DOI: https://doi.org/10.1016/ S0022-3476(81)80555-0

15. Ikuta L, Zukowsky K, Carter BM, Howard C. A 6th Vital Sign-Potential Use of Nasogastric Tube for Intraabdominal Pressure Monitoring Method to Detect Feeding Intolerance in Very Low Birth-Weight Preterm Infants (< 1500 g). Advances in Neonatal Care. 2015 Jun 1; 15(3): 17681. DOI: https://doi.org/10.1097/ANC.0000000000000175

16. Morag I, Hendel Y, Karol D, Geva R, Tzipi S. Transition From Nasogastric Tube to Oral Feeding: The Role of Parental Guided Responsive Feeding. Frontiers in pediatrics. 2019 May 9; 7: 190. DOI: https://doi.org/10.3389/ fped.2019.00190

17. Standley JM, Cassidy J, Grant R, Cevasco A, Szuch C, Nguyen J, Walworth D, Procelli D, Jarred J, Adams K. The effect of music reinforcement for non-nutritive sucking on nipple feeding of premature infants. Pediatric nursing. 2010 May 1; 36(3): 138.

18. Medoff-Cooper B, Rankin K, Li Z, Liu L, White-Traut R. Multi-sensory intervention for preterm infants improves sucking organization. Advances in neonatal care: official 
journal of the National Association of Neonatal Nurses. 2015 Apr; 15(2): 142. DOI: https://doi.org/10.1097/ ANC.0000000000000166

19. Gaebler CP, Hanzlik JR. The effects of a prefeeding stimulation program on preterm infants. American Journal of Occupational Therapy. 1996 Mar 1; 50(3): 184-92. DOI: https://doi.org/10.5014/ajot.50.3.184

20. Kron RE, Stein M, Goddard KE. A method of measuring sucking behavior of newborn infants. Psychosomatic Medicine. 1963 Mar 1; 25(2): 181-91. DOI: https://doi. org/10.1097/00006842-196303000-00010

21. Gerçek E, Sarıkaya Karabudak S, Ardıç Çelik N, Saruhan

A. The relationship between breastfeeding selfefficacy and LATCH scores and affecting factors. Journal of clinical nursing. 2017 Apr; 26(7-8): 994-1004. DOI: https://doi. org/10.1111/jocn.13423

22. Scherman A, et al. Quantification of nutritive sucking among preterm and full-term infants. Research and reports in Neonatology. 2018. DOI: https://doi.org/10.2147/RRN.S165421

23. Fucile S, Schanler RJ, Lau C. A Controlled-flow Vacuumfree Bottle System Enhances Preterm Infants' Nutritive Sucking skills. Dysphagia. 2009. DOI: https://doi. org/10.1007/s00455-008-9182-z

24. Barlow SM, Finan DS, Lee J, Chu S. Synthetic Orocutaneous Stimulation Entrains Preterm Infants with Feeding difficulties to suck. Journal of Perinatology. 2008. DOI: https://doi.org/10.1038/jp.2008.57
25. Poore M, Zimmerman E, Barlow SM, Wang J, Gu F. Patterned orocutaneous therapy improves sucking and oral feeding in preterm infants. Acta Paediatr. 2008. DOI: https://doi.org/10.1111/j.1651-2227.2008.00825.x

26. Barlow SM, et al. Frequency-modulated Orocutaneous Stimulation Promotes N on-nutritive Suck Development in Preterm Infants with Respiratory Distress Syndrome or Chronic Lung Disease. J Perinatal. 2014. DOI: https://doi. org/10.1038/jp.2013.149

27. Lau C, PhD, Kusnierczyk I. Quantitative Evaluation of Infants Non-nutritive and Nutritive Sucking. Dysphagia. 2001. DOI: https://doi.org/10.1007/s004550000043

28. Fucile S, Gisel EG, Lau C. Effect of an oral stimulation program on sucking skill maturation of preterm infants. Developmental Medicine \& Child Neurology. 2005 Mar; 47(3): 158-62. DOI: https://doi.org/10.1017/ S0012162205000290

29. Lefton-Greif MA, Carroll JL, Loughlin GM. Longterm followup of oropharyngeal dysphagia in children without apparent risk factors. Pediatric pulmonology. 2006 Nov; 41(11): 1040-8. DOI: https://doi.org/10.1002/ppul.20488

30. Boiron M, Nobrega LD, Roux S, Henrot A, Saliba E. Effects of oral stimulation and oral support on nonnutritive sucking and feeding performance in preterm infants. Developmental Medicine \& Child Neurology. 2007 Jun; 49(6): 439-44. DOI: https://doi.org/10.1111/j.14698749.2007.00439.x

\section{TO CITE THIS ARTICLE:}

Chandran R, Alagesan J. Oro-Motor Intervention Protocol to Improve Sucking Behavior among Neonates with Immature Sucking: An Experimental Protocol. International Journal of Surgery: Protocols. 2021; 25(1), pp. 129-134. DOI: https://doi.org/10.29337/ijsp.152

Submitted: 04 June 2021 Accepted: 15 July 2021 Published: 23 July 2021

\section{COPYRIGHT:}

(C) 2021 The Author(s). This is an open-access article distributed under the terms of the Creative Commons Attribution 4.0 International License (CC-BY 4.0), which permits unrestricted use, distribution, and reproduction in any medium, provided the original author and source are credited. See http://creativecommons.org/licenses/by/4.0/.

International Journal of Surgery: Protocols is a peer-reviewed open access journal published by IJS Publishing Group.

\section{IJS Press}

